\title{
Deformation behaviour of AA04 Alloy fly ash composites by using fem
}

\author{
Vijayalakshmi, M.Balaji \\ (assistant professor) vignan university,vadlamudi,Andra Pradesh,india.
}

\begin{abstract}
Composites are most promising materials of recent interest. Metal matrix composites (MMCs) possess significantly improved properties compared to unreinforced alloys. Composites with fly ash as reinforcement are likely to overcome the cost barrier for wide spread applications in automotive and small engine applications. In the present investigation, AA 2024 alloy $-10 \%$ fly ash composites were made by stir casting route. Phase identification and structural characterization was carried out on fly ash by X-ray diffraction studies. Scanning electron microscopy and optical microscopy was used for microstructure analysis. The hardness, compression and tensile tests were carried out on all these alloy and composites.

The variations in FEA results compared to analytical results for AA 2024 alloy and AA2024 alloy- $10 \%$ fly ash composites respectively. The obtained FEA results revealed that these values are closely matching with the experimental values with a maximum deviation of less than 5\%. Hence the FEA model adopted for solving the present upsetting analysis was validated with the analytical results.
\end{abstract}

Keywords: - Composite materials; stircasting route method; mechanical properties.

\section{INTRODUCTION}

Conventional monolithic materials have limitations in achieving good combination of strength, stiffness, toughness and density. To overcome these shortcomings and to meet the ever increasing demand of modern day technology, composites are most promising materials of recent interest. Metal matrix composites (MMCs) are an advanced materials resulting from a combination of two or more materials in which tailored properties are realized. MMCs possess significantly improved properties including high specific strength; specific modulus, damping capacity and good wear resistance compared to unreinforced alloys . In the last few years considerable development has occurred in the potential use of metal matrix composites for automotive applications. Considerable trails have been done on the use of metal matrix composites like aluminium-silicon carbide composites for connecting rods, brake rotors, drive shafts and several other components. However, cost still remains a major barrier in designing aluminium composite components for wider applications in automotive industries.

Compression Testing: The upset tests were performed at room temperature between two flat platens on a computer controlled UTM of $100 \mathrm{kN}$ capacity universal testing machine (Model: UT 9102; Dak System inc). The compression dies of $\mathrm{H} 11$ grade are used for compression and the sample is placed axi-symmetrically in between the dies. The tests were conducted at a constant cross head speed for both the alloy and composites for all the specimens. The compression tests were carried out until either 50\% reduction in height or initiation of the fracture on the specimen surface whichever is earlier. A PC based data logging system was used to record and store the loads and displacements continuously.

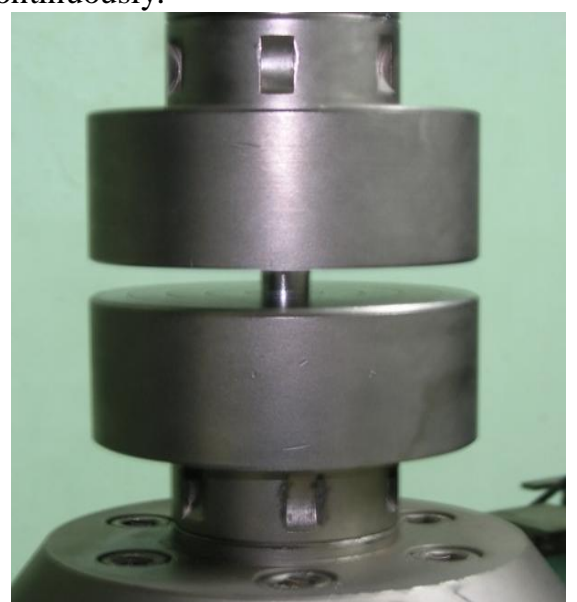

Experimental set of the Upset sample. 


\section{DISCUSSIONANDRESULTS}

The load displacement curves of the AA 2024 alloy and AA 2024 alloy fly ash (ALFA) composites. As the amount of fly ash is increasing the load carrying capacity also increasing. This could be due to the presence of fly ash particulates which consists of majority of the alumina and silica which are hard in nature.

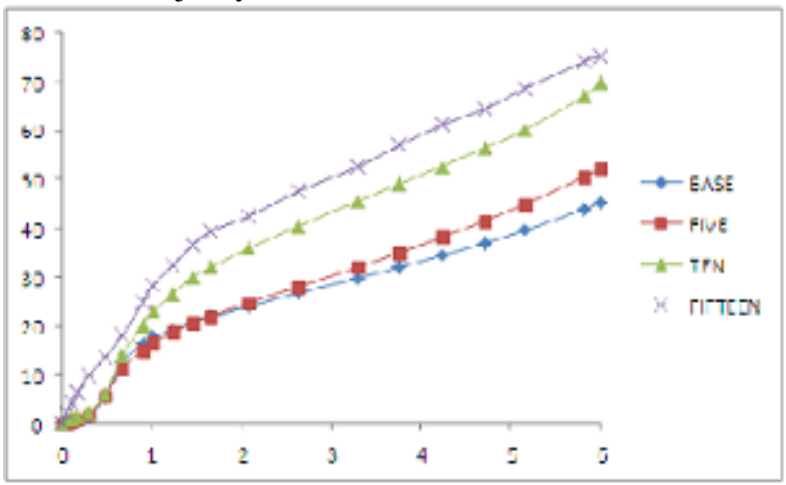

Load - displacement curves for A 2024 alloy and Al-Fly ash composites at the aspect ratio (Ho/Do) $=1.0$

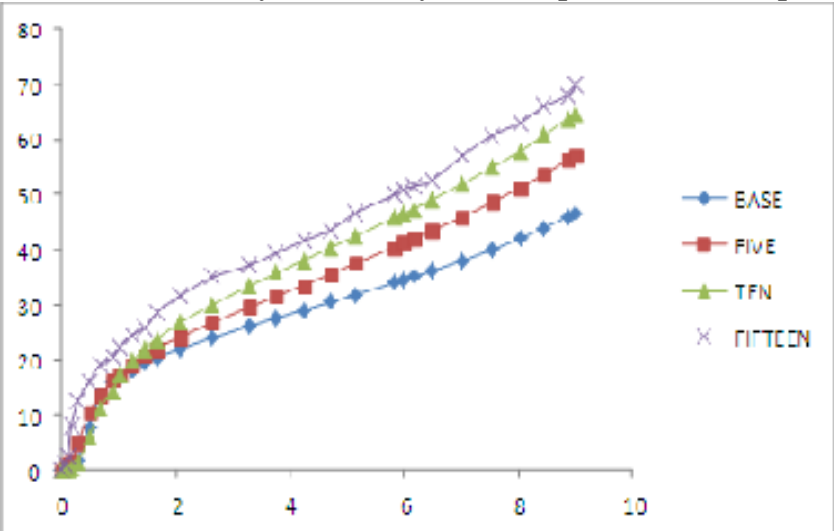

True stress vs true plastic strain for AA 2024alloy and Al-Fly ash composites at the aspect ratio (Ho/Do) $=1.5$

\section{FINITE ELEMENT MODELING}

The basic idea in the finite element analysis (FEA) is to find the solution of a complicated problem by replacing it by a simpler one. Since a simpler one to find the solution replaces the actual problem, we will be able to find only an approximate solution rather than the exact solution. The existing mathematical tools are not sufficient to find the exact solution of most of the practical problems. Thus in the absence of convenient method to find the approximate solution of 3-d problem, we have option for FEA. The FEA basically consists of the following procedure. First, a given physical or mathematical problem is modeled by dividing it into small interconnecting fundamental parts called Finite Elements.

$$
\text { Young's Modulus E }=220 \mathrm{GPa}=210 \times 10^{3} \mathrm{MPa}
$$

Poisson's ratio $v=0.30$

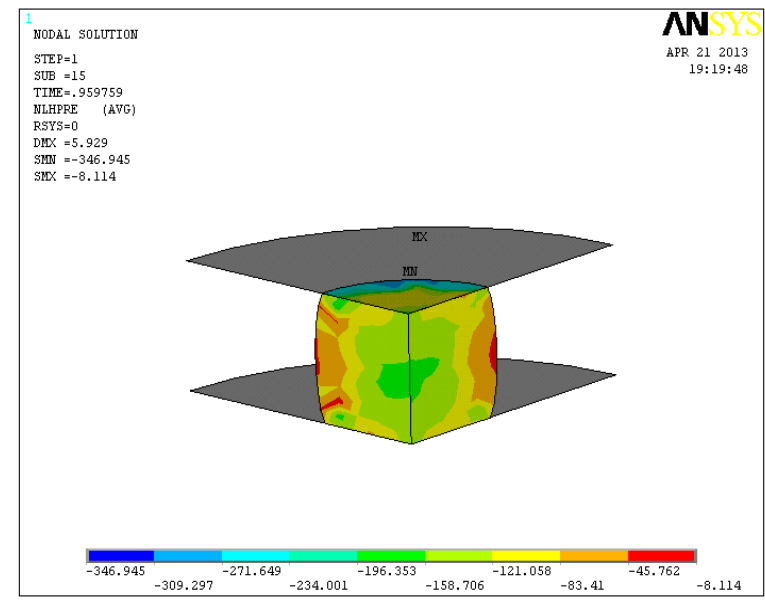

Hydrostatic Stress at 50\% deformation of AA 2024 alloy $\left(\mathrm{H}_{\mathrm{O}} / \mathrm{D}_{\mathrm{O}}=1.0\right)$ 


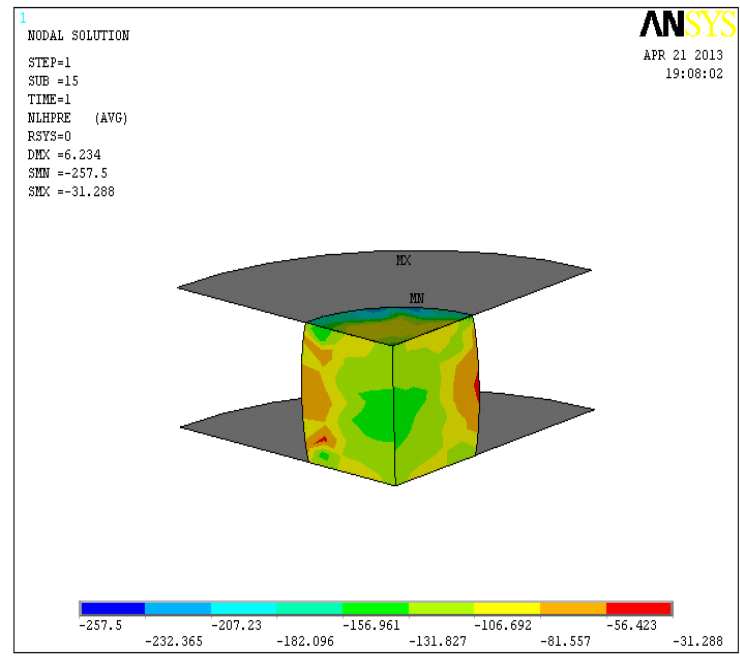

Hydrostatic Stress at 50\% deformation of AA 2024 alloy $\left(\mathrm{H}_{\mathrm{O}} / \mathrm{D}_{\mathrm{O}}=1.5\right)$

IV.

CONCLUSIONS

1. The cold upsetting process was modeled, simulated and analyzed with a sufficient accuracy.

2. The accuracy of results depends on the accuracy of the input data and friction model used in the analyses.

3. The time history data is useful in designing the intermediate dies for new materials.

4. The profile of the bulge during deformation can be estimated.

5. The analysis is useful in reducing the lead time of design cycle.

6. The machine down time can be reduced at production stage.

\section{REFERENCES}

[1] Weiss, D.: Using Metal Matrix composite castings, Proc. Symp. On Processing, properties and applications of CastMetalMatrix Composites, ed. P.K. Rohatgi (Cincinnati, 1996) 289.

[2] Siebel.E., Sathl and Eisen, DUSSELDORF, Vol.43; 1923: pp. 1295.

[3] Bishop J.F.W., J. Mech. Phys. Vol.6; 1958: pp. 132.

[4] Schroeder.W and D. A. Wevstrer, J. App. Mech. Vol. 16; 1949: pp. 289.

[5] Van Rooten G.T, and Gackofen W.A., Int. J. Mech. Sci., Vol. 1; 1960: pp.1.

[6] Daneshi G. H., and Hawkyard J. B., Int. J. Mech. Sci. Vol. 13; 1971: pp. 355.

[7] Kunogi, M., Reports of the Scientific Research Institute, Tokyo, Vol. 30; 1954: pp.63.

[8] Fukui, S., Ohi, T., Kudo, H., Takita, I., and Seino, J. "Some Aspects of Friction in Metal-Strip Drawing", Int.J. Mech. Sci., Vol 4; July-August, 1962: pp.297-314.

[9] Singaresu S Rao., "The Finite Element method in Engineering", Elsevier Butterworth-Heinemann 2005 edition. 